\title{
Fragilidade Ambiental: uma Proposta de Aplicação de Geomorphons para a Variável Relevo
}

\author{
Environmental Fragility: a Proposal of Applying Geomorphs \\ to a Relief Variable
}

\author{
Isabel Cristina Moroz-Caccia Gouveia ${ }^{\top} \bowtie$ (iD), Jurandyr Luciano Sanches Ross ${ }^{2} \bowtie$ \\ 1 Universidade Estadual Paulista Júlio de Mesquita Filho, ic.moroz@unesp.br, \\ https://orcid.org /0000-0001-6156-3446 \\ 2Universidade de São Paulo (USP), juraross@usp.br
}

Recebido (Received): 11/10/2018

Aceito (Accepted): 06/03/2019

\begin{abstract}
Resumo: Considerando a importância da variável relevo como determinante para a identificação de unidades de paisagem e para a análise de dinâmicas e processos relacionados à erosão dos solos e à ocorrência de inundações, o presente artigo propõe a incorporação de dados morfológicos a partir da classificação automatizada dos elementos de relevo (geomorphons), na análise da Fragilidade Ambiental. Foram elaborados mapas de Fragilidade Potencial e Fragilidade Emergente utilizando três modelos: A) Com parâmetros morfológicos (elementos de formas do relevo) extraídos de mapa geomorfológico elaborado analogicamente e parâmetros morfométricos (declividades), conforme recomendado por Ross (1990, 1994); B) Apenas a declividade como parâmetro morfométrico; e, C) Com parâmetros morfológicos (elementos de formas do relevo) extraídos automaticamente de MDE (geomorphons) e parâmetros morfométricos (declividades). Para avaliar cada modelo, aplicou-se o coeficiente de determinação linear $\left(\mathrm{r}^{2}\right)$ entre os níveis de fragilidade ambiental emergente determinados e a ocorrência de processos erosivos lineares identificados por IPT (2012). A comparação dos três modelos demonstrou que a inserção de parâmetros morfológicos permite determinar e delimitar os níveis de fragilidade de forma mais precisa e detalhada do que quando se utiliza apenas parâmetros morfométricos, como a declividade. Além do mais, a possibilidade de identificação de áreas de planícies fluviais nos modelos que incluem parâmetros morfológicos evita a classificação de tais áreas como sendo áreas sem restrições do meio físico à ocupação.
\end{abstract}

Palavras-Chaves: Parâmetros Morfológicos; Elementos de Formas do Relevo; Extração Automática; Presidente Prudente/SP.

Abstract: Considering the importance of the relief variable as a determinant for the identification of landscape units and for the analysis of dynamics and processes related to soil erosion and the occurrence of floods, the present article proposes the incorporation of morphological data from the automated classification of the elements (Geomorphons), in the analysis of the Environmental Fragility. We developed maps of Potential Fragility and Emergent Fragility using three models: A) With morphological parameters (elements of relief forms) extracted from an analogously elaborated geomorphological map and morphometric parameters (slopes), as recommended by Ross $(1990,1994)$; B) Only the slope as a morphometric parameter; and, C) With morphological parameters (elements of relief forms) automatically extracted from MDE (geomorphons) and morphometric parameters (slopes). To evaluate each model, the coefficient of linear determination $\left(\mathrm{r}^{2}\right)$ was applied between the determined levels of environmental fragility and the occurrence of linear erosive processes identified by IPT (2012). The comparison of the three models showed that the insertion of morphological parameters allows to determine and delimit of the fragility levels in a more precise and detailed way than when only morphometric parameters such as slope are used. Moreover, the possibility of identifying areas of fluvial plains in the models that include morphological parameters avoids the classification of such areas as being unrestricted areas from the physical environment to the occupation.

Keywords: Morphological Parameters; Elements of Relief Forms; Automatic Extraction; Presidente Prudente/SP. 


\section{Introdução}

Baseando-se no conceito de Unidades Ecodinâmicas de Tricart (1977), Ross (1990, 1994) propôs uma metodologia para a análise empírica da fragilidade de ambientes naturais e antropizados, com o objetivo de orientar estudos integrados aplicados ao planejamento territorial ambiental.

Ao longo de mais de um quarto de século, essa metodologia já consagrada foi amplamente utilizada em estudos ambientais voltados à análise e ordenamento físico-territorial, tanto no meio acadêmico quanto por órgãos públicos, estando inclusive presente nos conteúdos básicos para a elaboração de Zoneamentos Ecológicos-Econômicos (ZEE), instrumento da Política Nacional do Meio Ambiente regulamentado pelo decreto $\mathrm{n}^{\circ}$ 4.297/2002, com projetos realizados em diversas escalas de trabalho e em diversas partes do território nacional, como o Plano de Conservação da Bacia do Alto Paraguai, (BRASIL, 1997), ZEE do estado Paraná (PARANÁ, 2018) e Planos de Manejo de Unidades de Conservação, como Parque Estadual Intervales (SÃO PAULO, 2009), Parque Estadual Jurupará (SÃO PAULO, 2010) e APA Várzea do Tietê (SÃO PAULO, 2013).

Guirra et al. (2016) realizaram ampla revisão bibliográfica, buscando compreender a evolução técnica e científica e o caráter transdisciplinar de pesquisas que utilizam a metodologia de Fragilidade Ambiental. Os autores apontam como se deu a complementação, correlação e adaptação dos estudos aplicados sejam em bacias hidrográficas, perímetros urbanos ou rurais, buscando adequação as realidades que se impõem em cada território e destacam que o avanço das tecnologias de Sistemas de Informação Geográfica (SIGs) "permite a manipulação integrada de um grande número de variáveis, acessibilizando a geração de informações intermediárias e finais, ou a inclusão de outras variáveis não contempladas anteriormente" (p. 240). Dentre vários pesquisadores brasileiros que passaram a aplicar a metodologia de Ross $(1990,1994)$ utilizando SIGs, destacam-se Sporl (2007), Amaral e Ross (2009); Sporl, Castro e Luchiari (2011); Pinese Júnior e Rodrigues (2012); Massa e Ross (2012); Gayoso (2014); Ross e Fierz (2017), dentre outros.

Apesar dos avanços apontados por Guirra et al. (2016), no que diz respeito à variável relevo tem-se observado em muitos casos, sobretudo em estudos em escalas de detalhe ou média escala, uma simplificação da proposta inicial de Ross (1994). O autor afirma que para escalas médias e pequenas (1:50.000, 1:100.000, 1:250.000) deve-se utilizar como base de informação os Padrões de Formas Semelhantes ( $3^{\circ}$ táxon) com a rugosidade topográfica ou os Índices de Dissecação do Relevo, enquanto que para análises de maior detalhe (1:25.000, 1:10.000, por exemplo) utilizam-se as Formas de Vertentes ( $5^{\circ}$ táxon) e as classes de declividade (ROSS, 1994, p. 66). Entretanto, observa-se que alguns pesquisadores acabam utilizando apenas parâmetros morfométricos (declividades) em análises de detalhe e desconsideram aspectos morfológicos como as formas das vertentes (convexas, côncavas e retilíneas) e sequer destacam a ocorrência de planícies fluviais.

Compreende-se que tal fato decorre das dificuldades técnicas e do tempo dispendido para a elaboração de produtos cartográficos intermediários, no caso, um mapa geomorfológico de detalhe. Contudo, essa simplificação muitas vezes acaba induzindo a erros que podem, inclusive, ter implicações legais. Por exemplo, ao se considerar apenas a declividade como variável do relevo, as áreas de planícies fluviais podem ser classificadas como áreas de fragilidade do relevo Muito Baixa, pois situam-se entre 0 a $2 \%$ de declividades e, mesmo após a análise ponderada com as demais variáveis, acabam sendo classificadas com níveis de fragilidade que não correspondem à realidade. Quando se trata de documentos cartográficos que subsidiam o ordenamento territorial, incorre-se no erro de mascarar as restrições ambientais e legais de tais morfologias.

Ross e Fierz (2017) reelaboram a proposta inicial de Ross (1994), ressaltando a importância de destacar as áreas de planícies inundáveis como sendo áreas de fragilidade ambiental Muito Forte em função da instabilidade dos terrenos e ocorrência de inundações periódicas.

Conforme apontam Nepomuceno e Luchiari (2014) "o mapeamento morfológico consiste numa das etapas mais importantes do mapeamento geomorfológico, ele incorpora aspectos da morfografia, ou seja: do mapeamento qualitativo das formas que compõem um relevo" (pág. 198). Ainda de acordo com os autores, tradicionalmente o mapeamento morfológico é realizado a partir da fotointerpretação estereoscópica de fotografias aéreas, enquanto que os dados morfométricos são obtidos por meio da interpretação analógica de cartas topográficas.

Atualmente, face à disponibilidade de dados de sensoriamento remoto e geotecnologias, a obtenção de dados morfométricos se tornou uma tarefa bastante rápida e fácil, o que explica a utilização de mapas clinográficos como componente único da variável relevo na elaboração de mapas de fragilidade ambiental. Embora a obtenção de parâmetros morfológicos também seja facilitada a partir de técnicas digitais de extração de dados topográficos com o emprego de Modelos Digitais de Elevação (MDEs), os mesmos têm sido pouco utilizados nas análises de fragilidade ambiental. 
Valeriano (2008) afirma que atualmente o desenvolvimento de geotecnologias encontra-se longe de esgotar o potencial informativo dos dados topográficos existentes. A oferta de dados, a exemplo dos dados SRTM, possibilita o desenvolvimento de métodos mais flexíveis e "universais". (p.101)

Diversos autores tais como Christian e Stuart (1968); Tricart e Kilian, (1979); Dente e Young (1981); Ollier (1981) e Cooke e Doornkamp (1990) ressaltam a importância da Geomorfologia como elemento de integração de vários componentes da paisagem e como base na delimitação de unidades hierárquicas (FLORENZANO, 2008, p. 120).

Neste sentido, considerando a importância da variável relevo como determinante para a identificação de Unidades de Paisagem e para a análise de dinâmicas e processos relacionados à erosão dos solos e à ocorrência de inundações, o presente artigo propõe a utilização de parâmetros morfológicos (elementos de formas de relevo - geomorphons) obtidos a partir da extração automatizada de dados topográficos com o emprego de Modelos Digitais de Elevação (MDEs), como componente da variável relevo juntamente com parâmetros morfométricos como as classes de declividades, para a aplicação da metodologia de Fragilidade Ambiental em escalas de detalhe.

\section{Materiais e Métodos}

Para efeito de avaliação da metodologia ora proposta, elegeu-se como área piloto a porção norte município de Presidente Prudente - SP, onde se localizam pequenas bacias hidrográficas que drenam diretamente para o Rio do Peixe (Figura 1).

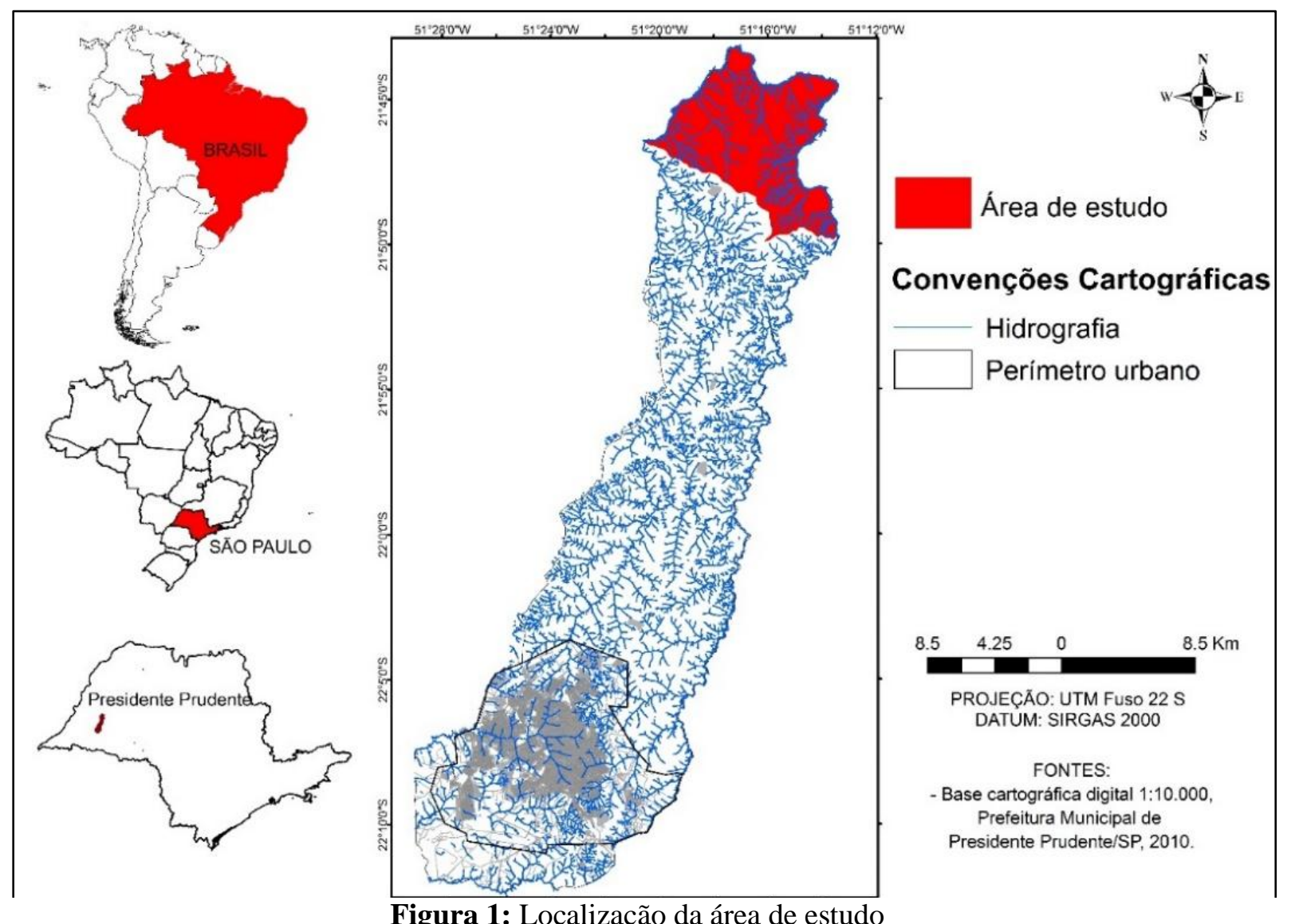

A área insere-se na unidade morfoestrutural $\left(1^{\circ}\right.$ táxon $)$ Bacia Sedimentar do Paraná, na unidade morfoescultural $\left(2^{\circ}\right.$ táxon) Planalto Ocidental Paulista, na sub-unidade denominada Planalto Centro Ocidental. Caracteriza-se por formas de relevos denudacionais, cujo modelado ou Tipos de Formas do Relevo (4 $4^{\circ}$ táxon) constitui-se basicamente em colinas amplas e baixas com topos convexos ou topos tabulares, com entalhamento dos vales geralmente inferiores a 20 metros e dimensões interfluviais médias, entre 1.750 e 3.750 metros (ROSS; MOROZ, 1997). Quanto aos aspectos geológicos, ocorrem na área arenitos da Formação Adamantina (Grupo Bauru), além de sedimentos aluvionares nas planícies fluviais (IPT, 1981). 
Como a área dispõe de mapeamento morfológico semidetalhado (MOROZ-CACCIA GOUVEIA et al., 2016, 2017) elaborado pelo método convencional de fotointerpretação, torna-se possível comparar os resultados obtidos em três situações distintas em relação à variável relevo:

A) Utilizando parâmetros morfológicos (elementos de formas do relevo $5^{\circ}$ táxon) extraído de mapa geomorfológico elaborado analógicamente e parâmetros morfométricos (declividades), conforme recomendado por Ross (1990, 1994);

B) Utilizando apenas as classes de declividades (parâmetros morfométricos) como tem sido aplicado por diversos autores; e.

C) Utilizando parâmetros morfológicos (elementos de formas do relevo - $5^{\circ}$ táxon) extraído automaticamente de MDE (geomorphons) e parâmetros morfométricos (declividades).

Para o modelo A utilizou-se os seguintes produtos cartográficos intermediários:

- Variável Relevo: Mapa Geomorfológico semidetalhado do município de Presidente Prudente - SP (MOROZ-CACCIA GOUVEIA et al., 2016), escala 1:25.000 (Figura 2) e Mapa Clinográfico (Figura 3), elaborado no SIG ArcGIS10.3, da ESRI, a partir dos dados de provenientes do radar SRTM (Shuttle Radar Topography Mission) disponibilizados pelo INPE.

- Variável Solos: Esboço Pedológico do município de Presidente Prudente - SP, escala 1:25.000 (Figura 4) (FUSHIMI; NUNES, 2015).

- Variável Uso e Cobertura da Terra: mapa elaborado a partir do Mapa de Cobertura da Terra do Estado de São Paulo, (SÃO PAULO, 2013), com base em imagens do satélite Landsat TM 5 do ano de 2010, na escala 1:100.000. Entretanto, como aquele produto cartográfico não diferencia áreas de cultivo, optou-se por extrair essa informação das imagens do Google Earth, de 2015. Assim, adicionou-se ao documento a categoria de uso e cobertura da terra referente ao plantio de cana-de-açúcar (Figura 5).

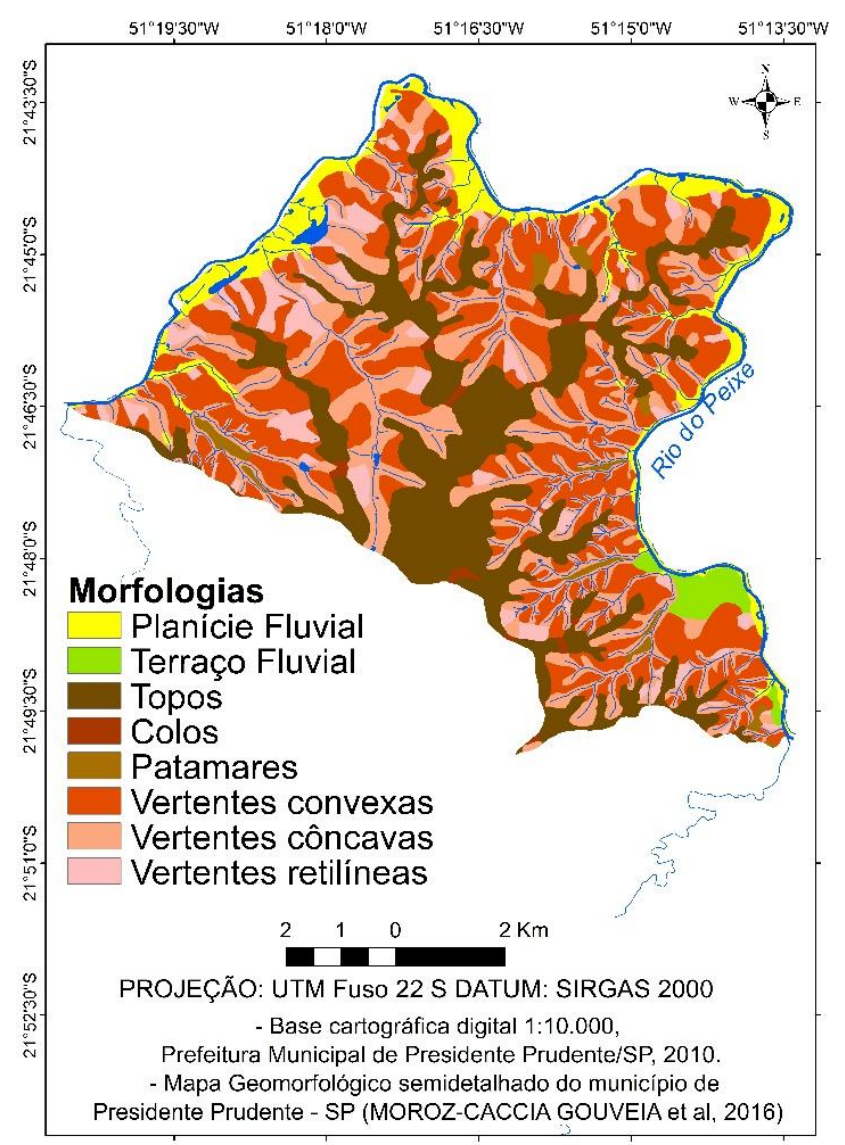

Figura 2: Mapa geomorfológico semidetalhado Fonte: Moroz-Caccia Gouveia et al. (2016).

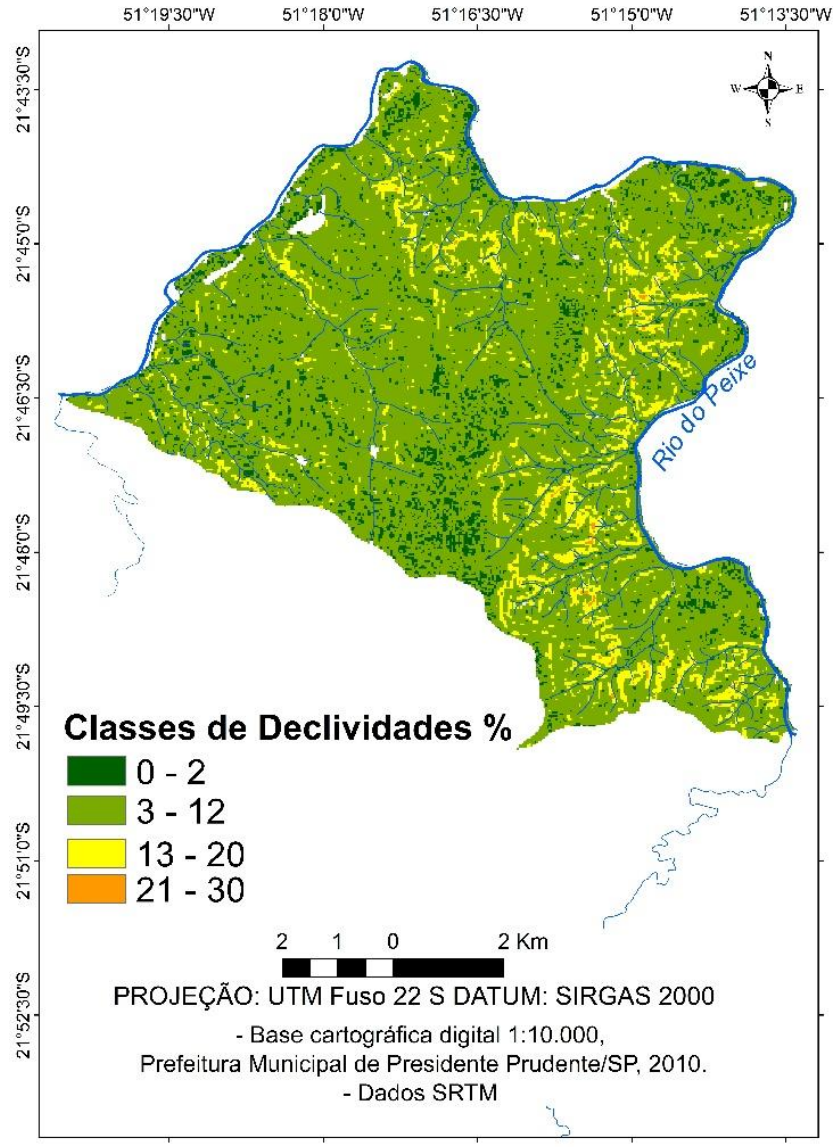

Figura 3: Mapa clinográfico Fonte: elaborado pelos autores 


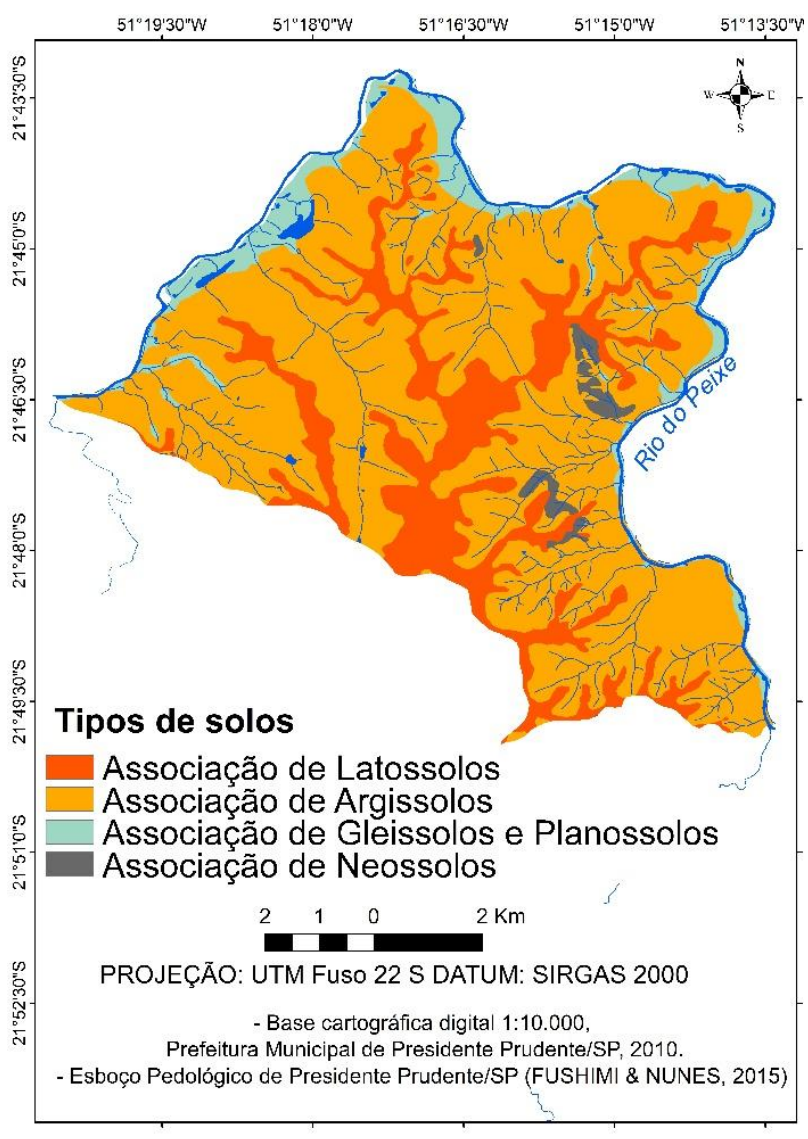

Figura 4: Esboço pedológico Fonte: Fushimi e Nunes (2015)

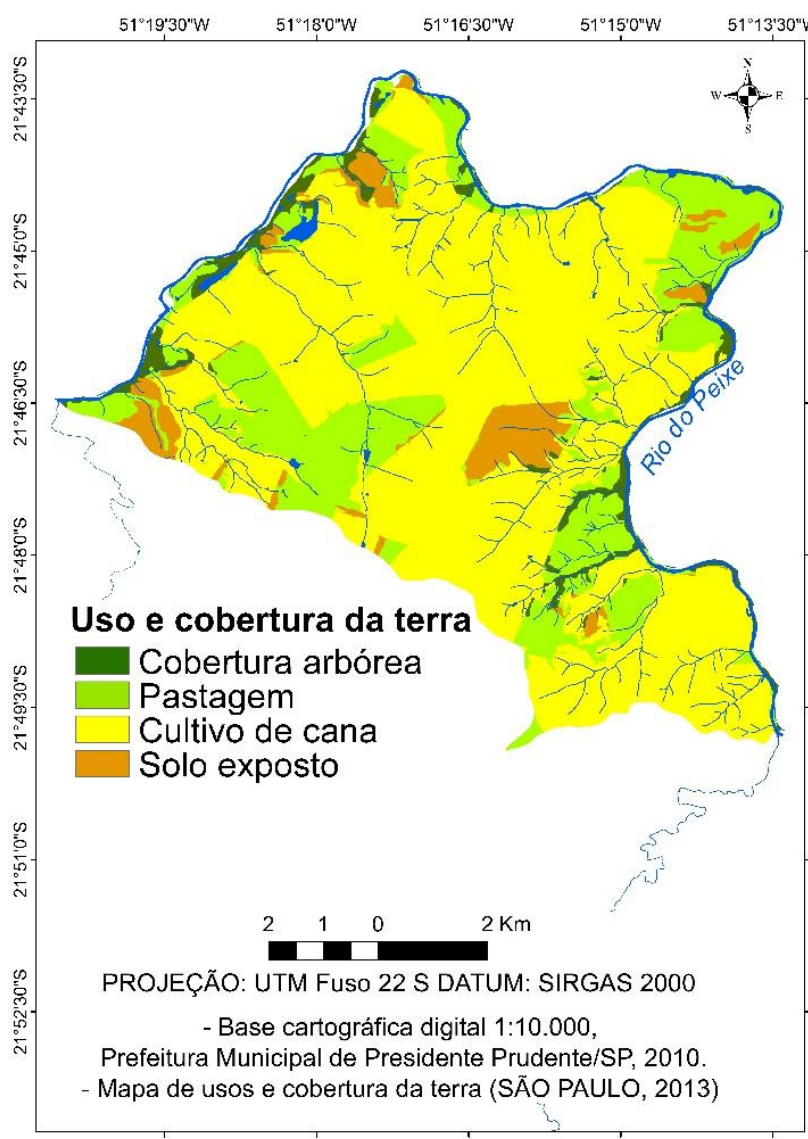

Figura 5: Uso e ocupação da terra Fonte: Adaptado de São Paulo (2013)

As sobreposições ponderadas foram realizadas através da ferramenta Weighted overlay (Spatial Analyst tools) do ArcGIS10.3, conforme Figura 6.

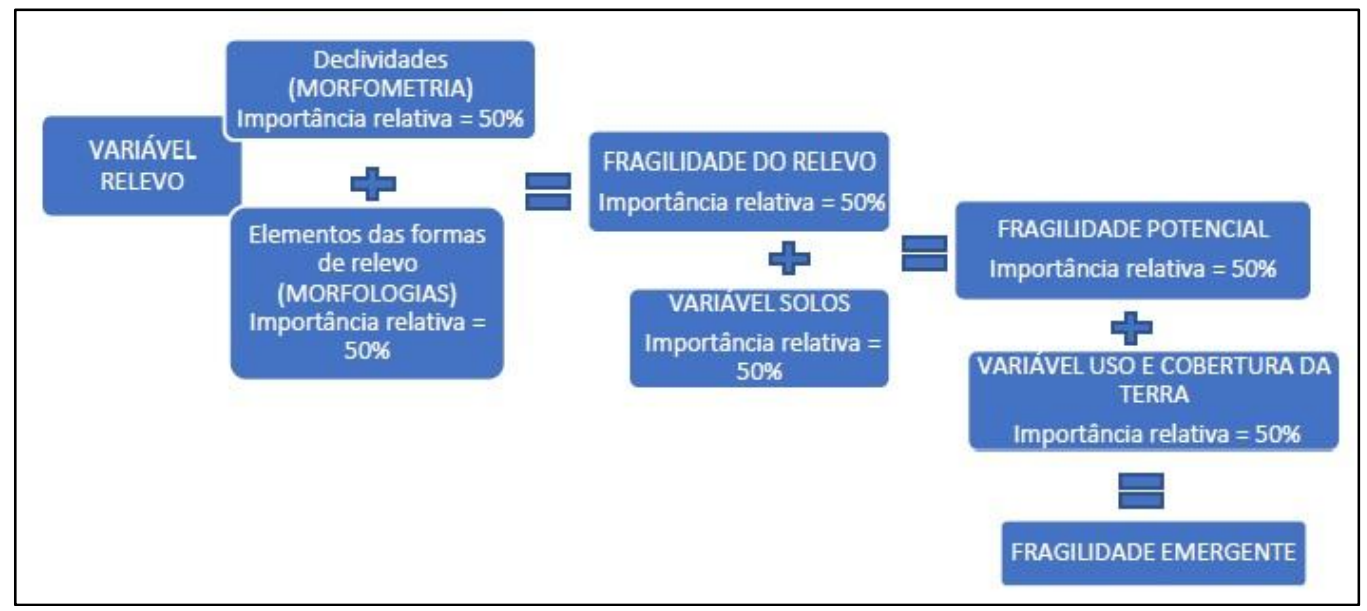

Figura 6: Fluxograma para produção de mapas de Fragilidade Potencial e Emergente de acordo com a metodologia A.

Para o modelo B utilizou-se para a variável Relevo apenas o mapa clinográfico (Figura 3). Para as variáveis Solos e Uso e Cobertura da Terra, foram utilizados os mesmos produtos cartográficos do modelo A (Figuras 4 e 5).

As sobreposições ponderadas também foram realizadas através da ferramenta Weighted overlay (Spatial Analyst tools) do ArcGIS10.3, conforme Figura 7. 


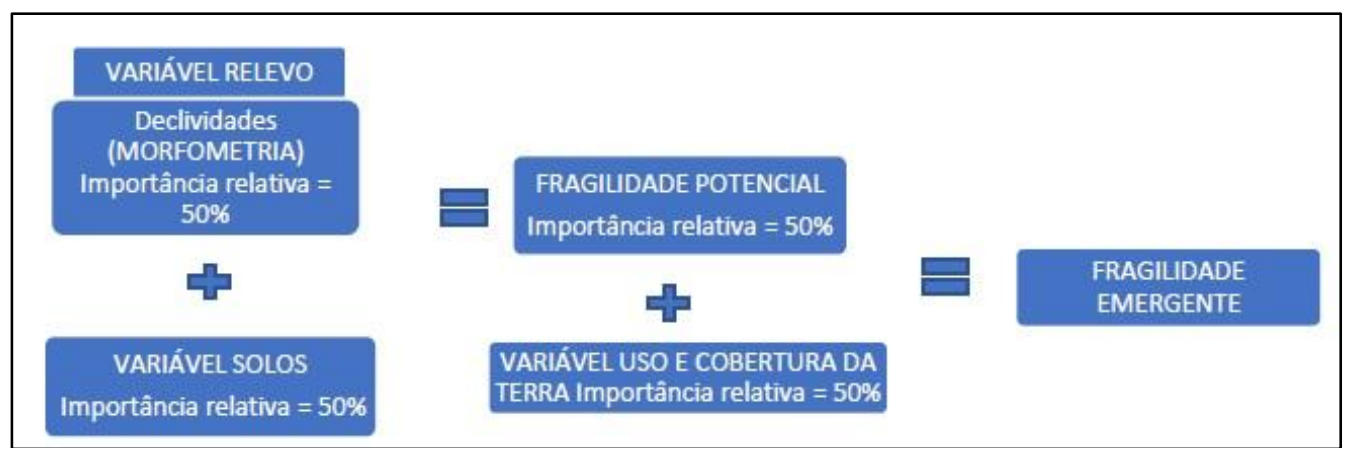

Figura 7: Fluxograma para produção de mapas de Fragilidade Potencial e Emergente de acordo com a metodologia B.

Para o modelo C utilizou-se os seguintes produtos cartográficos intermediários:

- Variável Relevo: Mapa de elementos das formas de relevo (geomorphons) (Figura 8) elaborado a partir dos dados de provenientes do radar SRTM através do aplicativo on-line (http://sil.uc.edu/geom/app) e Mapa Clinográfico (Figura 3).

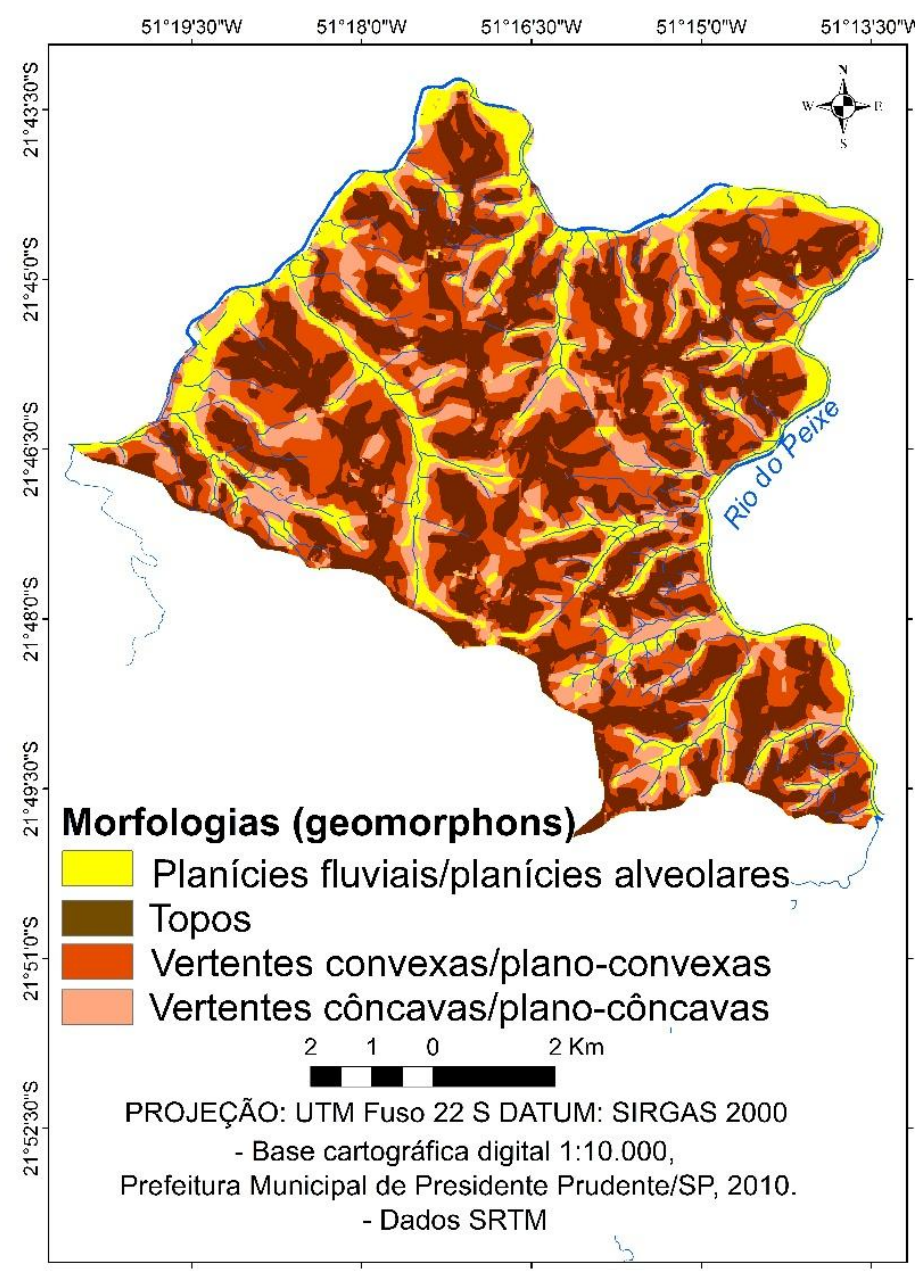

Figura 8: Mapa de elementos das formas de relevo (geomorphons). Fonte: elaborado pelos autores.

A proposta dos geomorphons (JASIEWICZ; STEPINSKI, 2013), analisa a similaridade textural do MDE, que apresentará variação de níveis de cinza entre células vizinhas, considerando que se a célula central for maior, assume o valor positivo “+”, se é menor, valor negativo “-” e se for igual seu valor é zero "0". Isso é transferido para valores de elevação do terreno de maior, menor ou igual.

No Brasil, a proposta foi aplicada pela primeira vez por Robaina et al. (2016) para a definição de compartimentos geomorfológicos no Rio Grande do Sul. 
Silveira et al. (2018), destacam que diversos autores apontam as vantagens do uso da classificação digital para a identificação do relevo, pois diminui a subjetividade da classificação manual, favorece a análise dos resultados derivados de diferentes conjuntos de dados e reduz o tempo de delineação das unidades. Ainda segundo os autores, "na abordagem da geomorfologia os geomorphons são compreendidos como microestruturas fundamentais do relevo" (p. 36).

A aplicação exige um conjunto de dados raster e dois valores escalares, livres, como parâmetros. O arquivo de entrada para a varredura é uma MDE. Os dois parâmetros livres são lookup L (distância em metros ou célula unidades) e threshold $\mathrm{t}$ (nivelamento em graus). Para os parâmetros livres aplicou-se valor de L igual a 20 pixels (1800 metros) e graus t igual a $2^{\circ}$, conforme Silveira et al. (2018). O aplicativo classifica 10 elementos de relevo (Figura 9): 1) áreas planas (flat), 2) picos (peak), 3) crista (ridge), 4) ressaltos (shoulder), 5) crista secundária (spur), 6) encosta (slope), 7) fosso (pit) 8) vales (valley), 9) base de encosta (footslope) e 10) escavado (hollow).

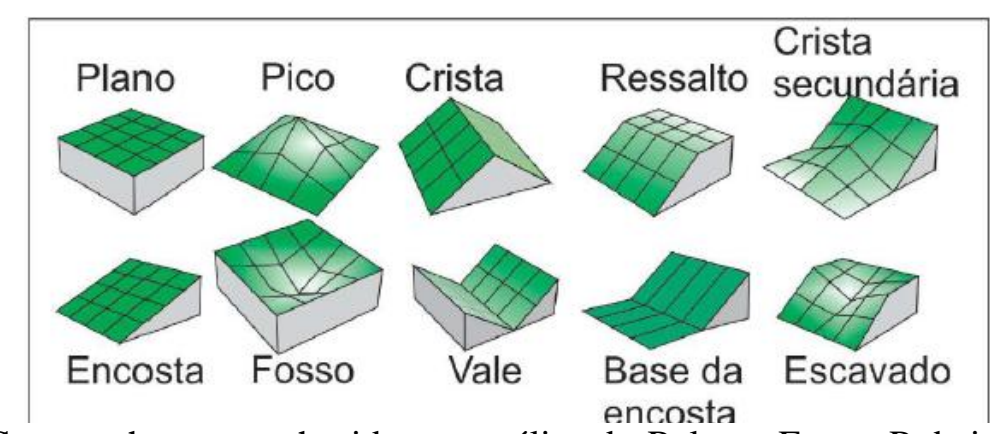

Figura 9: Principais Geomorphons reconhecidos na análise do Relevo. Fonte: Robaina, Trentin e Laurent (2016).

Para efeito de comparação com o mapa geomorfológico semidetalhado, posteriormente à identificação e análise da ocorrência dos geomorphons e com o auxílio dos mapas clinográfico e pedológico, estabeleceu-se a compartimentação do relevo através do agrupamento dos principais elementos. Assim, os fossos e vales por encontrarem-se em fundos de vale, em áreas de declividades inferiores a $6 \%$ e com presença de solos hidromórficos, foram identificadas como sendo Planícies de Inundação ou Planícies Alveolares. Os picos, cristas, ressaltos e as cristas secundárias foram generalizados e agrupados como Topos. As encostas foram classificadas como vertentes convexas e plano-convexas. As bases das encostas e escavados foram agrupados em vertentes côncavas e plano-côncava.

Para as variáveis Solos e Uso e Cobertura da Terra, foram utilizados os mesmos produtos cartográficos dos modelos A e B (Figuras 4 e 5)

As sobreposições ponderadas também foram realizadas através da ferramenta Weighted Overlay (Spatial Analyst tools) do ArcGIS10.3, conforme Figura 10.

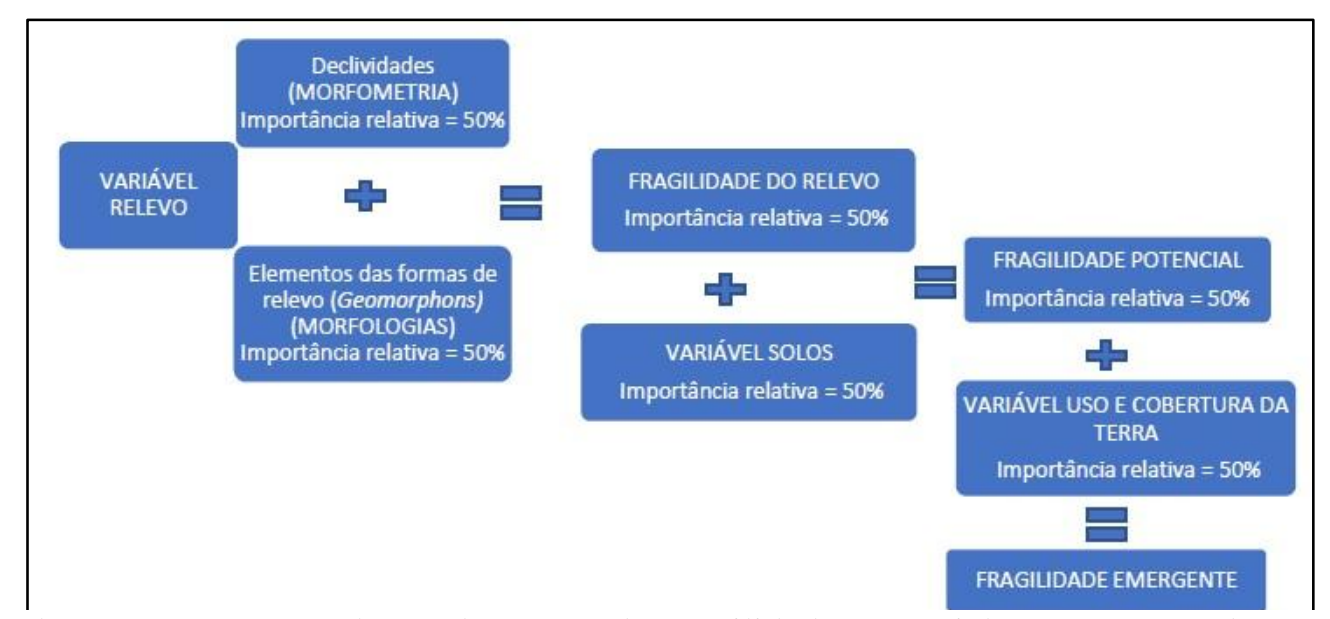

Figura 10: Fluxograma para produção de mapas de Fragilidade Potencial e Emergente de acordo com a metodologia $\mathrm{C}$. 
O Quadro 1 apresenta os graus de fragilidade atribuídos para cada componente das variáveis consideradas.

Quadro 1: Pesos atribuídos aos componentes das variáveis

\begin{tabular}{|c|c|c|c|c|c|}
\hline $\begin{array}{c}\text { Elementos das } \\
\text { formas de relevo } \\
\text { Modelo A }\end{array}$ & $\begin{array}{l}\text { Geomorphons } \\
\text { Modelo B }\end{array}$ & $\begin{array}{c}\text { Classes de } \\
\text { Declividades (\%) } \\
\text { Modelos A, B e C } \\
\end{array}$ & $\begin{array}{c}\text { Tipos de solos } \\
\text { Modelos A, B e C }\end{array}$ & $\begin{array}{c}\text { Classes de uso e } \\
\text { cobertura da terra } \\
\text { Modelos A, B e C } \\
\end{array}$ & $\begin{array}{l}\text { Níveis de } \\
\text { Fragilidade }\end{array}$ \\
\hline Topos aplanados & $\begin{array}{c}\text { Topos } \\
\text { (picos - 2, cristas - } 3 \text { e cristas } \\
\text { secundárias - 5) }\end{array}$ & $0-2$ & ----------- & Cobertura arbórea & $\begin{array}{l}1-\text { Muito } \\
\text { Baixo }\end{array}$ \\
\hline Patamares & -------- & $3-12$ & Latossolos & --------- & 2 - Baixo \\
\hline Vertentes convexas & $\begin{array}{l}\text { Vertentes convexas e plano- } \\
\text { convexas (Encostas - 6) }\end{array}$ & $13-20$ & ----------- & Cana-de-açúcar & 3 - Médio \\
\hline $\begin{array}{l}\text { Colos } \\
\text { Vertentes retilíneas } \\
\text { Terraco fluvial }\end{array}$ & --------- & $21-30$ & Argissolos & Pastagem & 4 - Alto \\
\hline Vertentes côncavas & $\begin{array}{l}\text { Vertentes côncavas e plano- } \\
\text { côncavas (bases das encostas - } 9 \text { e } \\
\text { escavados - 10) }\end{array}$ & $>30$ & Neossolos & Solo exposto & $\begin{array}{l}5-\text { Muito } \\
\text { Alto }\end{array}$ \\
\hline $\begin{array}{l}\text { Planície de } \\
\text { inundação }\end{array}$ & $\begin{array}{c}\text { Planície Fluvial } \\
\text { (fossos - } 7 \text { e vales - 8) }\end{array}$ & $0-2 \%$ & $\begin{array}{c}\text { Planossolos e } \\
\text { Gleissolos }\end{array}$ & ----------- & $\begin{array}{l}\text { Áreas sujeitas } \\
\text { a inundações }\end{array}$ \\
\hline
\end{tabular}

É preciso ressaltar que na área de estudos, os geomorphons identificados como picos receberam níveis de fragilidade Muito Baixo pois são pequenas elevações (menos de 1,0 m em relação ao entorno) presentes nos topos plano-convexizados. Em outros contextos de relevos mais dissecados, os valores de fragilidade devem ser revistos e adequados, assim como os critérios para o agrupamento dos geomorphons.

Para avaliar os resultados obtidos em cada modelo, aplicou-se o coeficiente de determinação linear $\left(\mathrm{r}^{2}\right)$ entre os níveis de fragilidade ambiental emergente determinados e a ocorrência de processos erosivos lineares (Figura 11) identificados por IPT (2012). O coeficiente de determinação possibilita avaliar a qualidade do ajuste de um modelo, ou seja, ele indica quanto o modelo foi capaz de explicar os dados observados na realidade ou sua capacidade preditiva. $\mathrm{O}^{2}$ varia entre 0 (zero) e 1 (um) e quanto mais próximo da unidade for o coeficiente de determinação, tanto maior será a validade da regressão. Assim, na presente pesquisa, o valor calculado refere-se aos níveis de fragilidade e os valores esperados correspondem à densidade de processos erosivos lineares verificados.

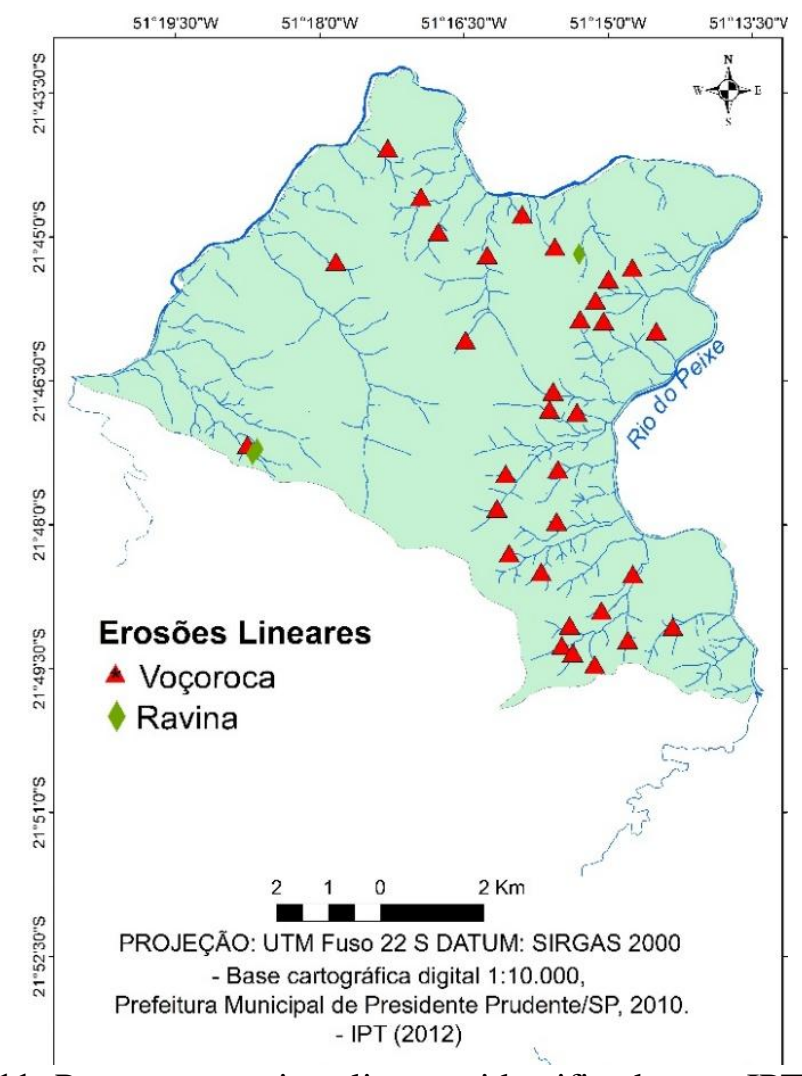

Figura 11: Processos erosivos lineares identificados por IPT (2012) 


\section{Resultados e Discussões}

A seguir apresentam-se os mapas de Fragilidade Potencial e Emergente produzidos de acordo com as três metodologias utilizadas. A Figura 12 mostra os mapas de Fragilidade (Potencial e Emergente) no modelo A.

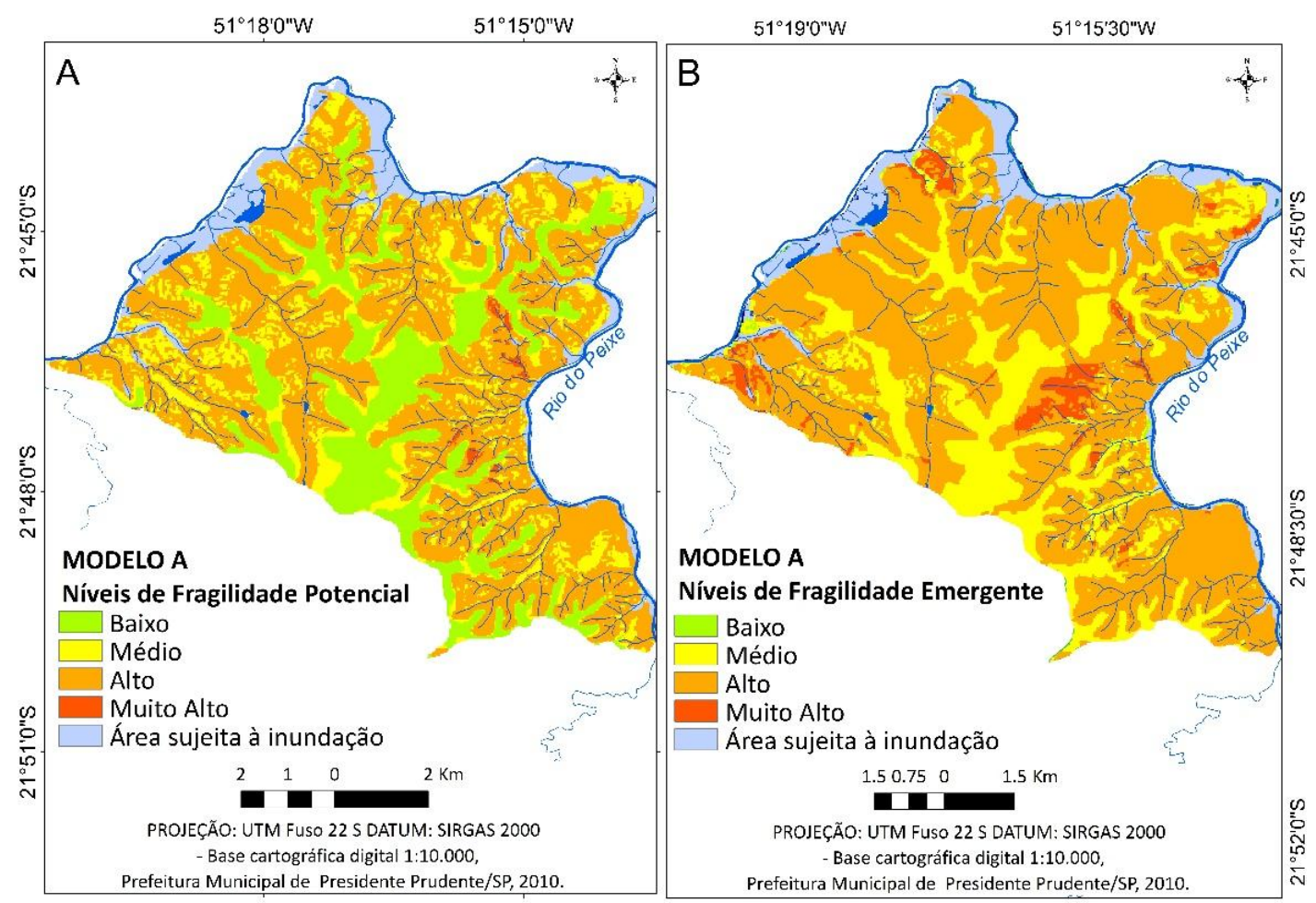

Figura 12: Mapa de Fragilidade Potencial (A) e Mapa de Fragilidade Emergente (B) de acordo com o modelo A.

A Figura 13 refere-se aos mapas de Fragilidade (Potencial e Emergente) no modelo B.
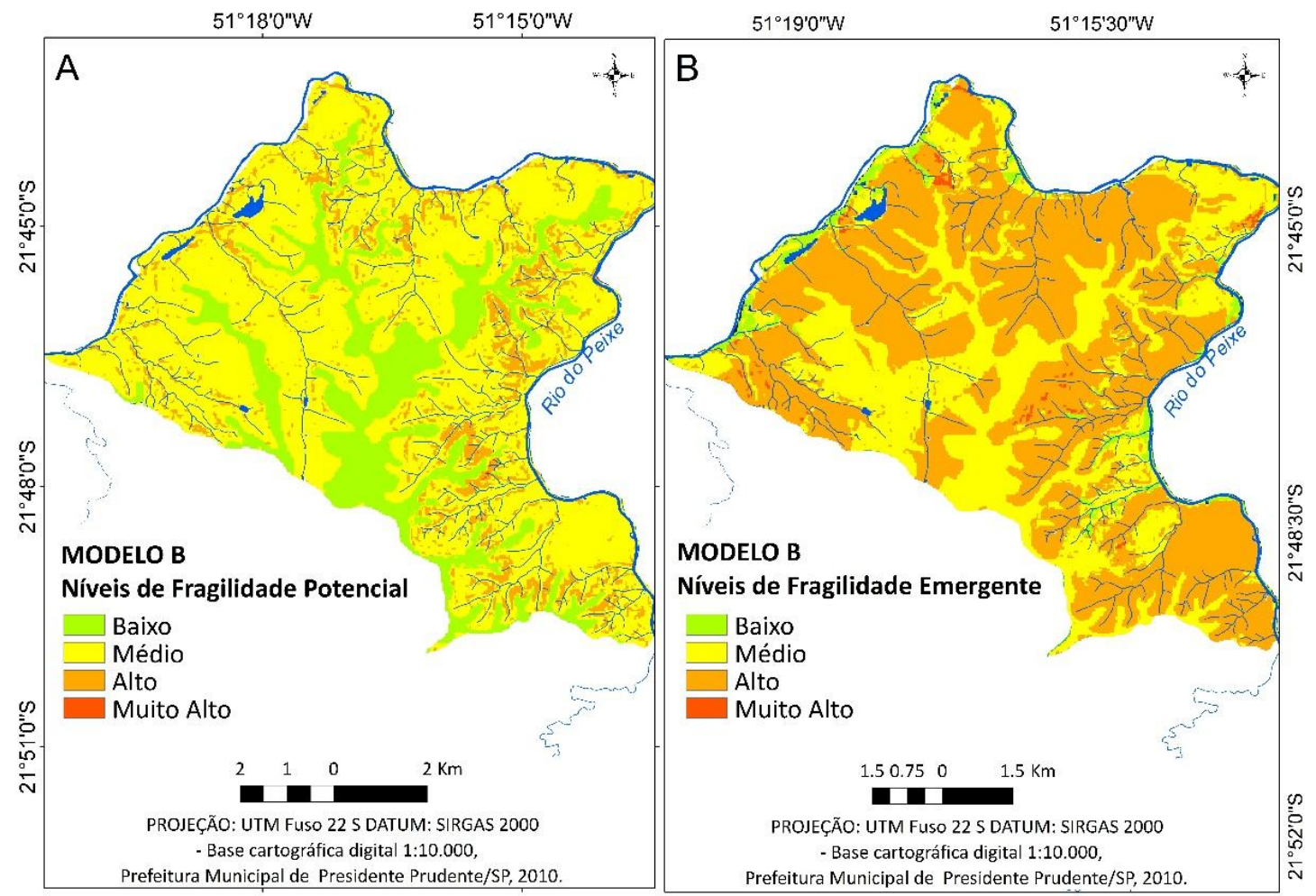

Figura 13: Mapa de Fragilidade Potencial (A) e Mapa de Fragilidade Emergente (B) de acordo com o modelo B. 
Observa-se que no modelo $\mathrm{B}$, utilizando apenas o mapa clinográfico para a variável relevo não é possível identificar áreas de planícies fluviais e, mesmo atribuindo nível de fragilidade Muito Alto para os solos hidromórficos na análise ponderada para gerar o mapa de fragilidade potencial, essas áreas acabam ficando com níveis de fragilidade médio, tanto no mapa de fragilidade potencial quanto no mapa de fragilidade emergente, em função das baixas declividades.

A Figura 14 refere-se aos mapas de Fragilidade (Potencial e Emergente) no modelo C.

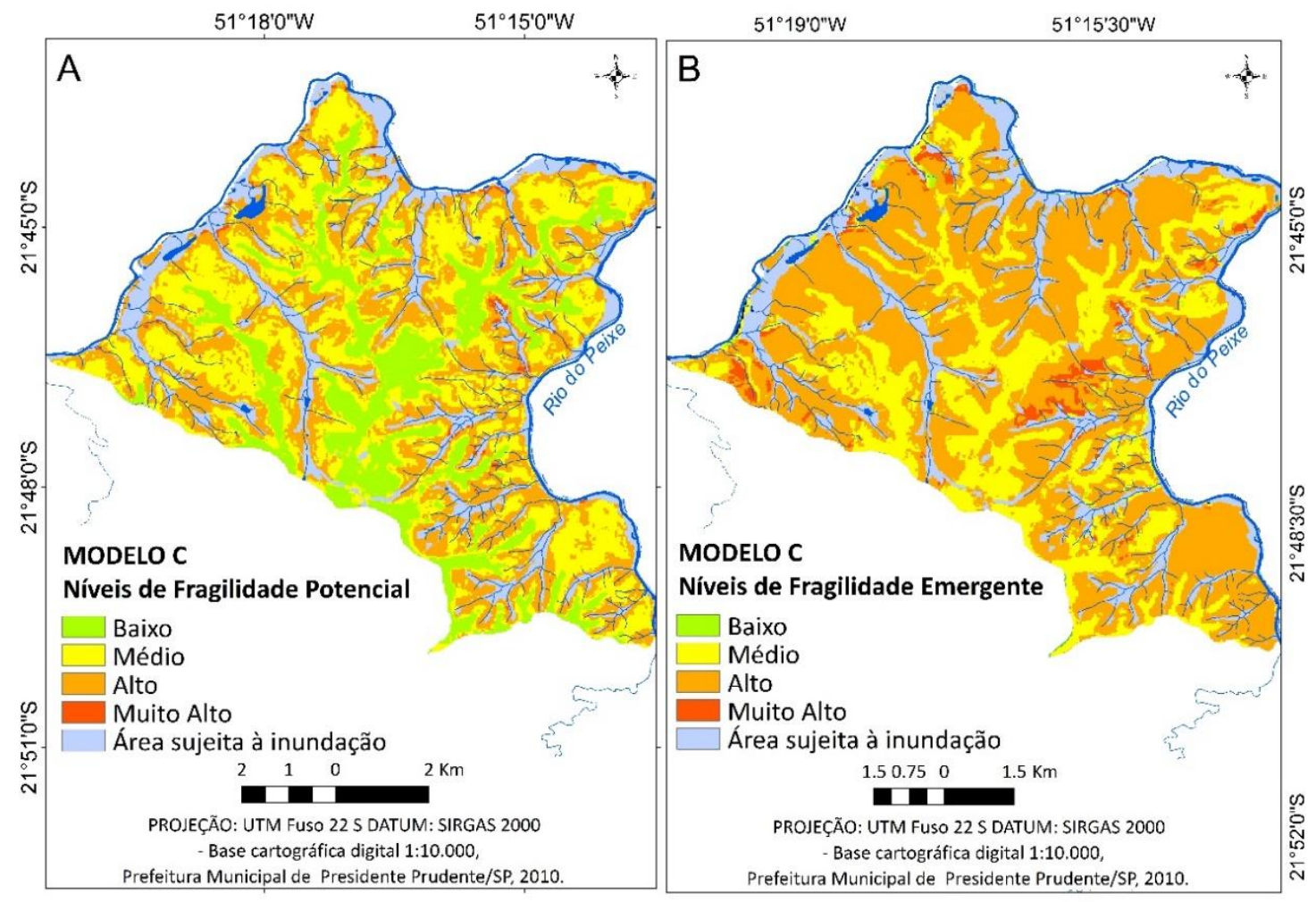

Figura 14: Mapa de Fragilidade Potencial (A) e Mapa de Fragilidade Emergente (B) de acordo com o modelo $\mathrm{C}$.

No modelo $\mathrm{C}$ observa-se a presença de algumas pequenas planícies fluviais e planícies alveolares que não foram identificadas no modelo A.

A Figura 15 apresenta uma comparação em relação às áreas ocupadas por cada nível de fragilidade, entre os mapas de Fragilidade Potencial gerados em cada modelo.

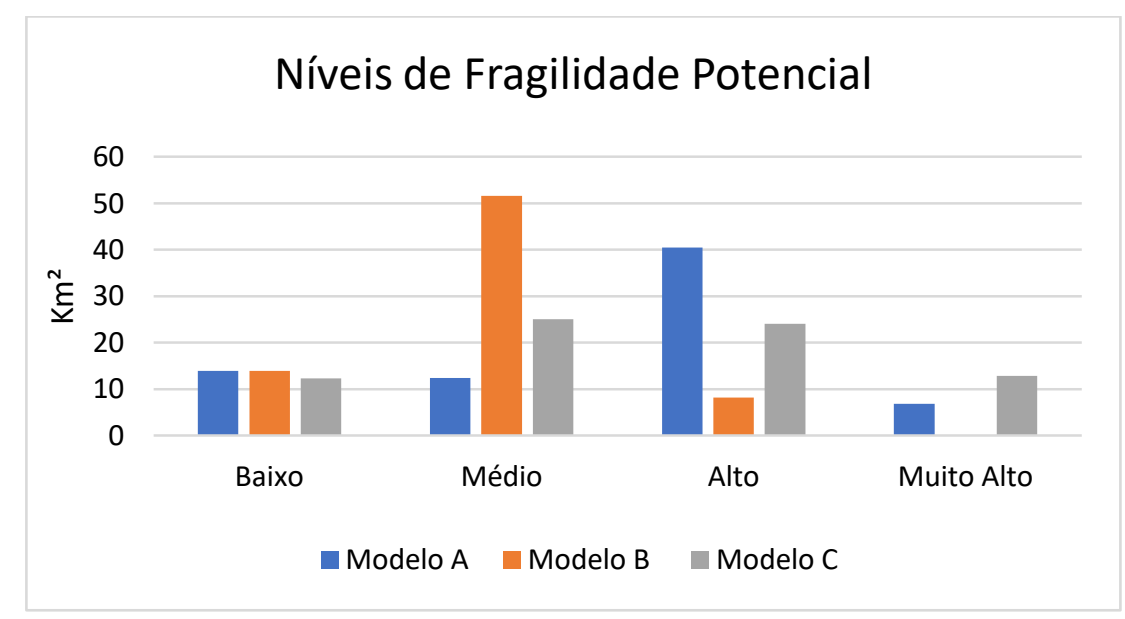

Figura 15: Comparação entre as áreas ocupadas por cada nível de Fragilidade Potencial nos três modelos. Elaborado pelos autores. 
Observa-se que no modelo A predominam áreas com nível de Fragilidade Alto. Já no modelo B, predominam áreas de fragilidade Média e no modelo $\mathrm{C}$, há um equilíbrio entre os níveis Médio e Alto. Ressalta-se ainda que no modelo B as áreas de fragilidade potencial Muito Alta são inexpressivas.

A Figura 16 apresenta uma comparação em relação às áreas ocupadas por cada nível de fragilidade, entre os mapas de Fragilidade Emergente gerados em cada modelo.

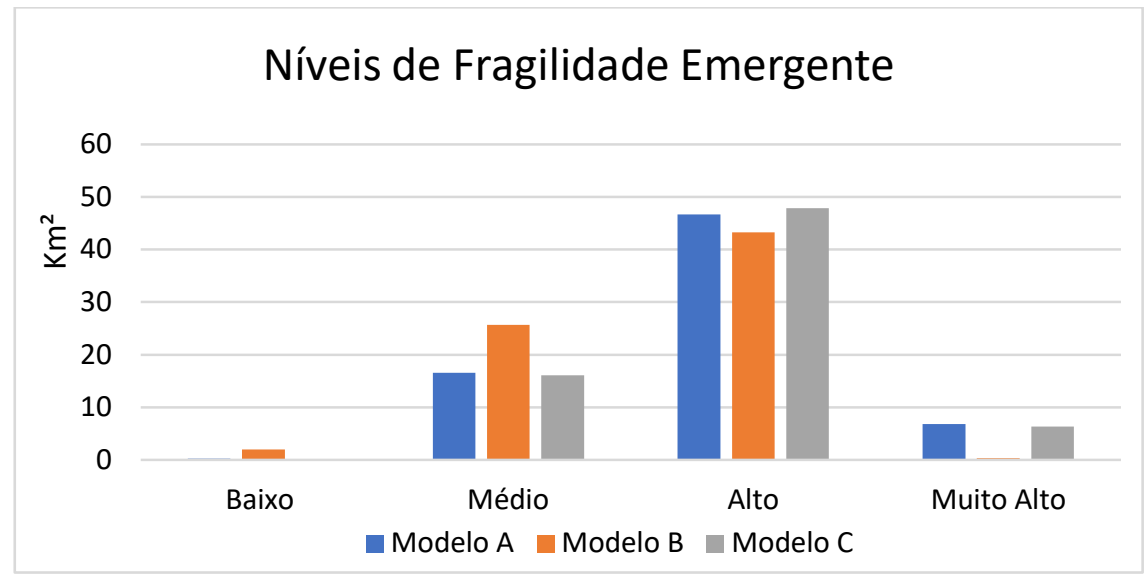

Figura 16: Comparação entre as áreas ocupadas por cada nível de fragilidade emergente nos três modelos. Elaborado pelos autores.

Observa-se similaridade entre os resultados obtidos nos modelos A e C, enquanto que no modelo B as áreas com de níveis Muito Alto de Fragilidade Emergente são inexpressivas.

Para avaliar os resultados obtidos nas três situações, aplicou-se o coeficiente de correlação entre os níveis de fragilidade ambiental identificados e a ocorrência de processos erosivos lineares identificados por IPT (2012).

De acordo com IPT (2012) na área ocorrem 35 focos de erosão linear, sendo 3 ravinas e 32 voçorocas.

Os focos de erosão ocorrem predominantemente em áreas de plantio de cana-de-açúcar e secundariamente, em áreas de solo exposto e pastagens. São áreas onde predominam os Argissolos e secundariamente, os Neossolos. Quanto às morfologias, as erosões predominam em áreas de vertentes côncavas. Em relação às declividades, não há um padrão de predominância, pois verificam-se focos até mesmo em áreas com declividade inferiores à $3 \%$.

A Figura 17 apresenta a correlação entre os níveis de fragilidade ambiental emergente determinados em cada modelo e a densidade de processos erosivos lineares (erosões/área) identificados por IPT (2012).

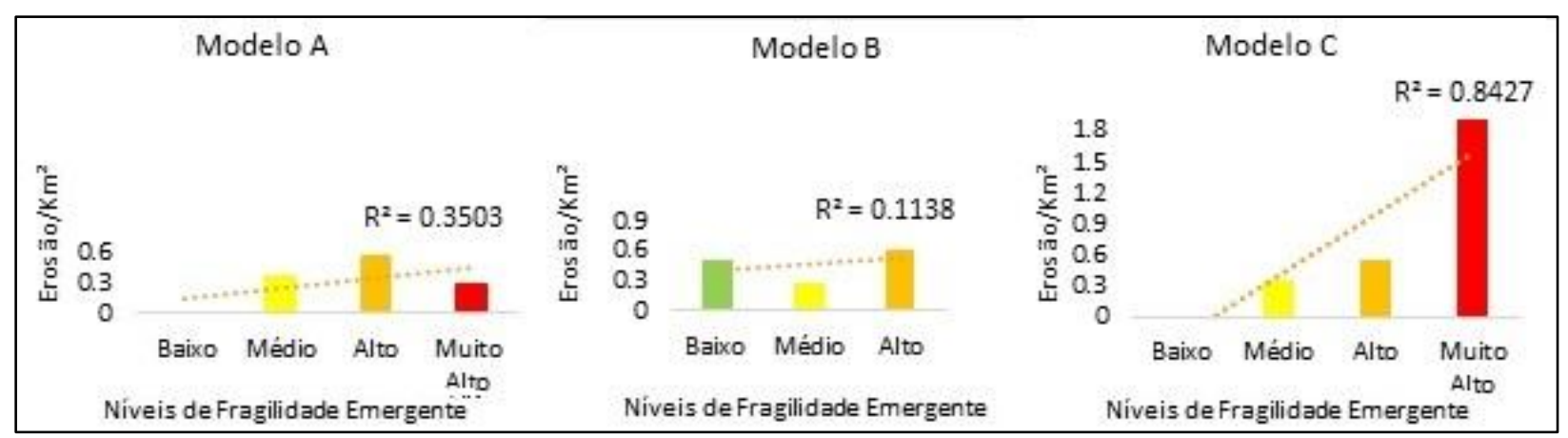

Figura 17: Níveis de fragilidade ambiental emergente determinados em cada modelo e a densidade de processos erosivos lineares (erosões/área).

O modelo A apresenta bom ajuste nos níveis Médio e Alto de Fragilidade Emergente, mas o nível Muito Alto apresenta discrepância em relação à densidade de erosão.

No modelo B, observa-se ajuste nos níveis Baixo e Alto e discrepância no nível Médio de Fragilidade Emergente. 
Já o modelo C apresenta ajuste nos níveis de Fragilidade Emergente. Como se pode observar, esse foi o modelo que obteve valor de $\mathrm{r}^{2}$ mais próximo de $1\left(\mathrm{r}^{2}=0,8427\right)$ o que indica coerência de $84,27 \%$ entre os valores de densidade de erosão observados e os níveis de fragilidade emergente determinados.

\section{Conclusões}

A utilização do método de extração e classificação automática geomorphons apresentou vantagens quando comparada à metodologia tradicional de mapeamento morfológico manual, pois implica em redução do tempo de trabalho e diminuição da subjetividade da interpretação visual de fotografias aéreas na identificação e delimitação de elementos de formas do relevo. Deste modo, a metodologia de geomorphons apresenta potencialidade para levantamentos morfológicos simplificados e necessita ser melhor explorada e testada em outros contextos geomorfológicos para uma melhor validação e compreensão acerca da calibração dos parâmetros livres utilizados no aplicativo.

Ressalta-se ainda que a disponibilidade de dados como o SRTM e MDEs e MDTs supre a ausência de fotografias aéreas, tão raras e escassas em muitas regiões do Brasil. Entretanto, é preciso alertar que as vantagens e facilidades oferecidas pelos métodos de extração automática de dados morfológicos ou morfométricos não diminuem a necessidade de acúmulo e domínio de conhecimentos por parte dos pesquisadores para interpretá-los e correlacioná-los na análise da paisagem.

A comparação dos três modelos demonstrou que a inserção de parâmetros morfológicos permite determinar e delimitar dos níveis de fragilidade de forma mais precisa e detalhada do que quando se utiliza apenas parâmetros morfométricos, como a declividade. Além do mais, a possibilidade de identificação de áreas de planícies fluviais nos modelos que incluem parâmetros morfológicos evita a classificação de tais áreas como sendo áreas sem restrições do meio físico à ocupação.

\section{Referências Bibliográficas}

AMARAL, R.; ROSS, J. L. S. As unidades ecodinâmicas na análise da Fragilidade Ambiental do Parque Estadual do Morro do Diabo e entorno, Teodoro Sampaio/SP. GEOUSP: Espaço E Tempo (Online), (26), 2009, 59-78.

BRASIL, Decreto $\mathbf{n}^{\circ}$ 4.297, de 10 de julho de 2002, regulamenta o art. $9^{\circ}$, inciso II, da Lei no 6.938, de 31 de agosto de 1981, estabelecendo critérios para o Zoneamento Ecológico-Econômico do Brasil - ZEE, e dá outras providências. Disponível em: http://www.planalto.gov.br/ccivil_03/decreto/2002/d4297.htm>.Acesso em: 12 set. 2018.

BRASIL. Plano de Conservação da Bacia do Alto Paraguai - PCBAP. Ministério do Meio Ambiente, dos Recursos Hídricos e da Amazônia Legal Programa Nacional do Meio Ambiente. Brasília: PNMA, 1997.

CHRISTIAN, K. F.; STUART, G. A. Methodology of Integrated Survey in Aerial Surveys and Integrated Studies, UNESCO, Paris, 1968, p. 233-280.

COOKE, R. U.; DOORNKAMP, J. C. Geomorphology in Environmental Management. An Introduction, $2^{\mathrm{a}}$ ed., Claredon Press, Oxford, 1990.

DENT, D.; YOUNG, A. Soil Survey and land evaluation. George Allen \& Unwin, London, 1981.

FLORENZANO, T, G, Cartografia In; FLORENZANO, T, G. (org.). Geomorfologia: conceitos e tecnologias atuais. São Paulo: Oficina de Textos, 2008, p. 105-128.

FUSHIMI, M.; NUNES, J. O. R. Principais classes de solos no município de Presidente Prudente - SP: Identificação e caracterização. Boletim Goiano de Geografia, vol. 32, Goiânia, 2015, p. 45-58.

GAYOSO, R. C. Fragilidade ambiental e vulnerabilidade social para análise integrada do espaço geográfico: bacia hidrográfica no Jardim Ângela (São Paulo - SP) [Dissertação]. São Paulo: Faculdade de Filosofia, Letras e Ciências Humanas, Universidade de São Paulo; 2014, 162p.

GUIRRA, A. M. P. et al. (2016) A evolução metodológica de Fragilidade Ambiental no Brasil e seu aspecto transdisciplinar In: Anais do IV Simpósio Nacional sobre Cidades Pequenas, Universidade Federal de Uberlândia | Observatório das Cidades, Ituiutaba, 2016, p. 234-250. 
IPT - INSTITUTO DE PESQUISAS TECNOLÓGICAS DO ESTADO DE SÃO PAULO. Cadastramento de pontos de erosão e inundação no Estado de São Paulo, Relatório Técnico 131.057 - 205 Departamento de Águas e Energia Elétrica - DAEE, São Paulo, 2012.

JASIEWICZ, J.; STEPINSKI, T. F. Geomorphons - a pattern recognition approach to classification and mapping of lanforms. Geomorphology, n. 182, p. 147-156. 2013.

MASSA, E.; ROSS, J. L. Aplicação de um modelo de Fragilidade Ambiental relevo-solo na Serra da Cantareira, bacia do Córrego do Bispo, São Paulo - SP. Revista do Departamento de Geografia, 24, São Paulo, 2012, 57-79.

MATO GROSSO, SECRETARIA DE PLAEJAMENTO (SEPLAN), Zoneamento Ecológico-Econômico do Mato Grosso, Cuiabá, 2008.

MINISTÉRIO DO MEIO AMBIENTE (MMA). Diretrizes metodológicas para o Zoneamento EcológicoEconômico do Brasil. 2006.20 Disponível em: <http://www.mma.gov.br/estruturas/PZEE/_arquivos/diretrizes_2006_parte1.pdf>. Acesso em: 12 set. 2018

MOROZ-CACCIA GOUVEIA, I. C.; NUNES, J. O. R.; FUSHIMI, M. Relevo. In: NUNES, J. O. R et al. (Org.). Atlas ambiental escolar de Presidente Prudente, São Paulo, Brasil. 1ed.PRESIDENTE PRUDENTE: Ed. do Autor, 2017, v. 1, ISBN (978-85-60554-14-0), p. 11-20. Disponível em: http://portaldoprofessor.fct.unesp.br:9000/

MOROZ-CACCIA GOUVEIA, I. C.; NUNES, J. O.; GOUVEIA, J. M. C.; FUSHIMI, M. Mapa geomorfológico semidetalhado do município de Presidente Prudente - SP. In: Anais do XI Simpósio Nacional de Geomorfologia, Maringá, 2016. Disponível em http://www.sinageo.org.br/2016/trabalhos/6/658-668.html.

NEPOMUCENO, P.; LUCHIARI, A. Mapeamento morfológico de detalhe: Experiências para a integração entre técnicas de Fotointerpretação e Sistemas de Informações Geográficas no Município de Salesópolis SP. Revista do Departamento de Geografia, 28, São Paulo, 2015, 198-220.

OLLIER, C. D. Terrain classification methods: Application and principles. In: HAILS, J. R. (Ed) Applied Geomorphology: A Perspective of the contribution of geomorphogy studies and environmental management. Elsevier Scientific Publishing Company, Amsterdam, 1981, p 277-316.

PARANÁ, SECRETARIA DE ESTADO DO MEIO AMBIENTE E RECURSOS HÍDRICOS - SEMA/ INSTITUTO DE TERRAS, CARTOGRAFIA E GEOCIÊNCIAS - ITCG Zoneamento EcológicoEconômico do estado do Paraná, 2018. Disponível em: http://www.itcg.pr.gov.br/modules/conteudo/conteudo.php?conteudo=168

PINESE JÚNIOR, J.; RODRIGUES, S. O método de análise hierárquica - AHP - como auxílio na determinação da vulnerabilidade ambiental da bacia hidrográfica do Rio Piedade (MG). Revista do Departamento de Geografia, 23, São Paulo, 2012, 4-26.

ROBAINA, L. E. de S.; TRENTIN, R.; LAURENT, F. Compartimentação do Estado do Rio Grande do Sul, Brasil, através do uso de Geomorphons obtidos em Classificação Topográfica Automatizada. Revista Brasileira de Geomorfologia (Online), v. 17, n. 2, São Paulo, 2016, p. 287 - 298.

ROSS, J. L. S. Landforms and environmental planning: potentialities and fragilities Revista do Departamento de Geografia, volume especial 30 anos, São Paulo, 2012, p. 38-52

ROSS, J. L. S. Ecogeografia do Brasil: subsídios para planejamento ambiental. São Paulo: Oficina de Textos, 2006. 208p

ROSS, J. L. S. Geomorfologia aplicada aos EIAs-RIMAs. In: GUERRA, A. J. T. \& CUNHA, S. B. da (org.). Geomorfologia e meio ambiente. Bertrand Brasil: Rio de Janeiro, 1996. p 291 -336

ROSS, J. L. S. et al. Plano de conservação da bacia do Alto Paraguai, Ministério do Meio Ambiente, Brasília, 1995.

ROSS, J. L. S. Análise empírica da fragilidade dos ambientes naturais e antropizados. Revista do Departamento de Geografia, 8, São Paulo, 1994. p. 63-74

ROSS, J. L. S. Geomorfologia: ambiente e planejamento. São Paulo: Contexto, 1990. 88p.

ROSS, J. L. S.; FIERZ, M. de S. M. Geomorfologia aplicada ao planejamento ambiental territorial: potencialidades e fragilidades in: MAGNONI JÚNIOR, L. et al. (orgs) Redução do risco de desastres e a resiliência no meio rural e urbano, Centro Paula Souza, São Paulo, 2017. p.58-77 
ROSS, J. L. S.; MOROZ, I. C. Mapa Geomorfológico do estado de São Paulo escala 1:500.000. São Paulo: Laboratório de Geomorfologia, Departamento de Geografia FFLCH - USP/IPT/FAPESP: vols. I e II, São Paulo,1997, vols I e II.

SANTOS, J. de O. Relações entre Fragilidade Ambiental e Vulnerabilidade Social na susceptibilidade aos riscos, Revista Mercator, v. 14, n. 2, Fortaleza, 2015, p. 75-90.

SÃO PAULO, CPLA/SMA, Mapeamento de cobertura da terra do estado de São Paulo - 2010 - Escala 1:100.000 - Coordenadoria de Planejamento Ambiental, Secretaria do Meio Ambiente do estado de São Paulo, São Paulo, 2013 Disponível em: <http://www2.ambiente.sp.gov.br/cpla/cessao-de-dados/> Acesso em 27 de ago. 2018. SÃO PAULO, SECRETARIA DE MEIO AMBIENTE/INSTITUTO FLORESTAL. Plano de Manejo da APA Várzea do Rio Tietê, São Paulo. 2013

SÃo PAUlO, SECRETARIA DE MEIO AMBIENTE INSTITUTO FlORESTAL. Plano de Manejo do Parque Estadual de Intervales. São Paulo. 2009

SÃO PAUlO, SECRETARIA DE MEIO AMBIENTE/INSTITUTO FLORESTAL. Plano de Manejo do Parque Estadual do Jurupará, São Paulo. 2010.

SILVEIRA, C. T. da et al. Classificação automatizada de elementos do relevo no estado do Paraná (Brasil) por meio da aplicação da proposta dos geomorphons. Revista Brasileira de Geomorfologia. (Online), v.19, n.1, São Paulo, 2018, p.33-57

SPÖRL C. Metodologia para elaboração de modelos de fragilidade ambiental utilizando redes neurais [tese]. São Paulo: Faculdade de Filosofia, Letras e Ciências Humanas, Universidade de São Paulo; 2007. 185 $\mathrm{p}$

SPÖRL, C.; CASTRO, G. E.; LUCHIARI, A. Aplicação de Redes Neurais Artificiais na Construção de Modelos de Fragilidade Ambiental, Revista do Departamento de Geografia, 21, São Paulo, 2011, p. 113135.

TRICART, J. Ecodinâmica. Rio de Janeiro: IBGE, Diretoria Técnica, SUPREN, Rio de Janeiro, 1977. 91 p.

TRICART, J. ; KILIAN, J. L'éco-géographie et L'amenagement du Milieu Naturel., François Masfero, Paris, 1979.

VALERIANO, M. de M. Dados Topográficos in: FlORENZANO, T. G (Org.) Geomorfologia: conceitos e tecnologias atuais. São Paulo: Oficina de Textos, 2008. p. 72- 104 